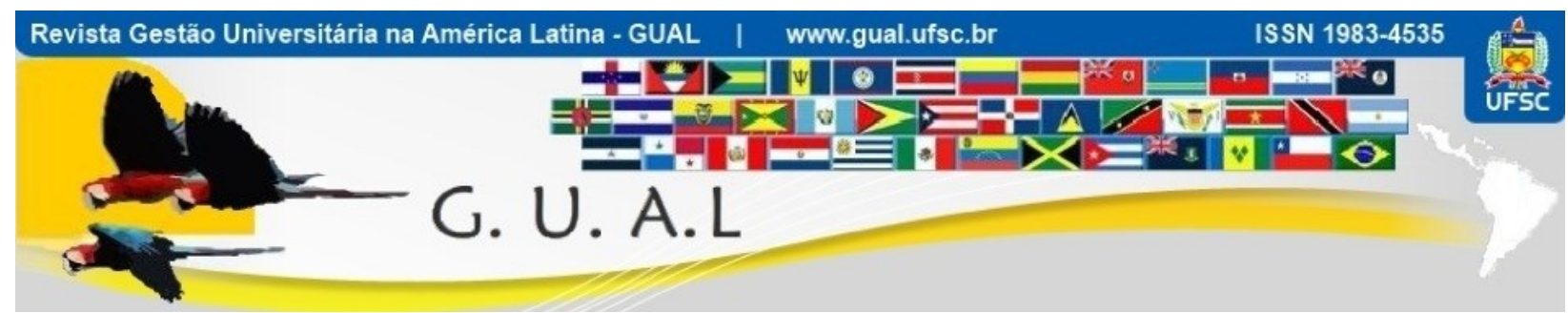

DOI: http://dx.doi.org/10.5007/1983-4535.2018v11n2p274

\title{
PERCEPÇÕES SOBRE A NATUREZA HUMANA E DAS RELAÇÕES PROFISSIONAIS NO TRABALHO DE SERVIDORES UNIVERSITÁRIOS
}

\section{PERCEPTIONS ABOUT THE HUMAN NATURE AND LABOR PROFESSIONAL RELATIONS OF UNIVERSITY EMPLOYEES}

Thiago Soares Nunes, Doutor

Centro Universitário UNA Universidade Federal de Santa Catarina - UFSC adm.thiagosn@gmail.com

Suzana da Rosa Tolfo, Doutora Universidade Federal de Santa Catarina - UFSC s.r.tolfo@ufsc.br

Leonor María Cantera Espinosa, Doutora Universidade Autônoma de Barcelona - UAB leonor.cantera@uab.cat

Recebido em 27/setembro/2016

Aprovado em 30/novembro/2017

Sistema de Avaliação: Double Blind Review

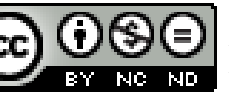

Esta obra está sob uma Licença Creative Commons Atribuição-Uso. 


\title{
RESUMO
}

As organizações definem, de forma explícita ou implícita, o "modelo" de comportamento e de relacionamento interpessoal no âmbito laboral, o qual é influenciado pela própria cultura organizacional e nacional. Por sua vez, identificar a concepção a natureza humana e a dos relacionamentos interpessoais são importantes aspectos para desvendar elementos visíveis e invisíveis presentes no cotidiano organizacional. Desta forma, esta pesquisa teve por objetivo descrever a percepção dos servidores docentes e técnico-administrativos da Universidade Federal de Santa Catarina em relação a aspectos culturais como concepções sobre a natureza humana e relacionamento profissional no âmbito laboral. A pesquisa foi classificada como descritiva, quanti-quali, e estudo de caso. Os dados foram coletados por meio de questionário online (214 respostas) e entrevistas (12 entrevistados), e foram tratados estatisticamente e também por meio de análise de conteúdo. Os resultados enfatizam que os servidores docentes apresentam uma imagem "positiva" em relação a concepção de trabalhadores, ao contrário dos técnico-administrativos, que tiveram um perfil mais "negativo". Os mesmos são vistos como preguiçosos e descomprometidos com o trabalho, características estas atribuída aos servidores públicos conforme a cultura do serviço público. Por sua vez, os relacionamentos profissionais tendem a ser mais amigáveis nos setores, ao contrário do que ocorre na UFSC como um todo, que tendem para conflituosos. Além disto, ficou evidenciado o conflito entre categorias, que persiste há muito tempo na Universidade.

Palavras-chave: Servidor. Docente. Técnico-Administrativo. Universidade. Relacionamento profissional.

\begin{abstract}
Organizations define, explicitly or implicitly, the model of behavior and interpersonal relationships in the workplace, which is influenced by the organizational and national culture. In turn, identifying the conception of human nature and interpersonal relationships is important to reveal noticeable and unnoticeable elements present in the organizational routine. Bearing this in mind, this research aimed to describe the perception of professors and technical-administrative employees from the Federal University of Santa Catarina (UFSC) in relation to the cultural aspects as conceptions about the human nature and workplace relationships. The research was classified as descriptive, quantitative and qualitative, and case study. The data was collected through an online survey, with 214 responses, and then 12 interviews were conducted. After that, the results were analyzed statistically and through content analysis. Finally, it was possible to infer that professors have a positive image regarding the conception of workers, whereas technical-administrative employees have a more negative profile, since they are seen as lazy and uncommitted to work. These characteristics are attributed to public employees according to public service culture. On the other hand, the professional relationships are inclined to be friendlier in the sectors, differently from what usually happen at UFSC as a whole, which tend to be conflictive. Moreover, it was possible to notice that there is a conflict between the categories, which have persisted for a long time in the university.
\end{abstract}

Keywords: Public employees. Professor. Technical-administrative. University. Professional relationships. 


\section{INTRODUÇÃO}

Vivemos em uma sociedade brasileira onde há uma cultura forte do "jeitinho", do paternalismo, da lealdade às pessoas, da impunidade (PRATES; BARROS, 1997; ALCADIPANI; CRUBELLATE, 2003). Tais características muitas vezes se concretizam em práticas ambivalentes, propícias a diferenças ou dissonâncias entre o discurso e a prática entre trabalhadores, gestores e organizações, que favorecem situações de desigualdade e assédio moral. As organizações e universidades públicas embora tenham como foco servir à sociedade, apresentam também estas características e práticas, além de outras como a supervalorização da burocracia e da hierarquia, apego ao poder.

A cultura de uma organização orienta as relações interpessoais que são estabelecidas por meio das atividades no âmbito do trabalho (FREITAS; HELOANI; BARRETO, 2008). Não somente a cultura da organização exerce influência, mas também a própria cultura nacional e do serviço público. Nesta perspectiva, é importante conhecer e observar os elementos que constituem a cultura da organização, a forma como eles funcionam e as mudanças comportamentais que proporcionam, os quais podem auxiliar em uma compreensão mais detalhada de aspectos despercebidos na vida organizacional cotidiana. A partir disso, é possível compreender e identificar fatores culturais visíveis e invisíveis nas organizações, e com isso levantar elementos que influenciam as práticas saudáveis ou hostis.

Uma maneira de identificar tais fatores é compreender e entender o indivíduo e seus relacionamentos interpessoais no ambiente laboral. Isto implica em decifrar os pressupostos básicos que formam a cultura da organização, em especial as suposições culturais que refletem sobre a natureza humana e dos relacionamentos humanos (SCHEIN, 2009). No âmbito organizacional, estudos sobre a natureza humana procuram identificar/descrever como os trabalhadores são vistos (SCHEIN, 2009), por exemplo, se são leais ou desleais, independentes ou dependentes, comprometidos ou descomprometidos. Já a natureza dos relacionamentos humanos, define a maneira que as pessoas se relacionam e a distribuição de poder (SCHEIN, 2009).

Desta forma, compreender essas naturezas, tendo como objetos de análise os servidores de uma instituição pública de ensino superior, possibilita entender até que ponto a cultura organizacional, nacional e do serviço público influenciam na percepção que cada um destes tem sobre o outro e sobre si e também a sua relação entre eles e com outros setores. Com isso, é possível identificar aspectos que necessitam de ação da gestão e comunidade interna e 
externa para confrontar aspectos negativos que possam aparecer, uma vez que evidencia-se que ambas categorias historicamente apresentam conflitos e disparidades entre si (NUNES, 2011).

Para tanto, este artigo tem por objetivo descrever a percepção dos servidores docentes e técnico-administrativos da Universidade Federal de Santa Catarina em relação a aspectos culturais como concepções sobre a natureza humana e relacionamento profissional no âmbito laboral.

\section{REVISÃO DA LITERATURA}

Ao entrar em qualquer organização o que primeiramente observamos são elementos concretos, como a arquitetura, os moveis e equipamentos, o movimento de pessoal, ou seja, fatores de fácil observação. No entanto, os indivíduos, responsáveis por manter (e criar) a cultura e práticas organizacionais, não são peças/engrenagens de máquinas, rígidas, imutáveis, eles apresentam comportamentos, sentimentos de amizade e hostilidade, cooperação e competição, formam grupos, criam regras e normas para sobrevivência.

Para se compreender uma organização e seu funcionamento, é importante conhecer sua cultura e práticas organizacionais. Um dos autores mais conceituados e utilizados tanto no âmbito internacional quanto nacional é Edgar Schein (FLEURY, 1987; FLEURY, 1996; FREITAS, 2007). Para Schein (2009, p. 16) a cultura organizacional é definida como:

[...] um padrão de suposições básicas compartilhadas, que foi aprendido por um grupo à medida que solucionava seus problemas de adaptação externa $\mathrm{e}$ integração interna. Esse padrão tem funcionado bem o suficiente para ser considerado válido, e, por conseguinte, para ser ensinado aos novos membros como o modo correto de perceber, pensar e sentir-se em relação a esses problemas.

Segundo Schein (2009), a cultura pode ser analisada em diferentes níveis, uma vez que estes níveis variam de manifestações abertas muito tangíveis, que podemos ver e sentir, à suposições básicas, inconscientes e profundamente inseridas. Para o autor, entre estas camadas estão as várias crenças, normas e regras de comportamento e valores assumidos pelos membros da organização.

Para alcançar um nível mais profundo de compreensão da cultura organizacional, é necessário adentrar no nível dos Pressupostos Básicos, que "de modo geral são tão naturais que as pessoas não questionam ou não se dão conta que os mesmos orientam seus 
comportamentos" (SILVA, 2001, p. 40). Eles compreendem as crenças, percepções, pensamentos e sentimentos inconscientes criados pelos indivíduos para orientar seus comportamentos, as quais são assumidas como verdadeiras pelo grupo e determinam como um membro deve perceber, pensar e sentir o trabalho, as metas de desempenho, as relações humanas e o desempenho dos colegas, e demais (SCHEIN, 2009). Bem como dizem respeito à visão de mundo implicada na natureza das relações essenciais ao indivíduo como ambiente, o tempo, o espaço, outro indivíduo e o trabalho (FREITAS, 2007).

Quando um pressuposto básico passa a ser assumido fortemente pelo grupo, qualquer comportamento contrário será considerado como fora do "padrão". Nesta perspectiva, os pressupostos básicos são similares ao que Argyris (1976, apud SCHEIN, 2009) denomina como theories-in-use, onde as suposições implícitas orientam o comportamento e ditam aos membros do grupo como perceber, refletir e sentir as coisas. O poder da cultura decorre do compartilhamento dos pressupostos, os quais são compartilhados pelos membros que têm a "mesma forma de pensar", ou seja, são reforçadas e enraizadas na cultura da organização.

Dentre as dimensões ou naturezas das quais são formadas os pressupostos básicos, destacamos Natureza da Natureza Humana e a Natureza dos Relacionamentos Humanos, os quais foram trabalhadores neste artigo. As suposições sobre a Natureza da Natureza Humana procura definir sobre o que significa o "ser humano", quais os instintos básicos, os tipos de comportamentos que são considerados humanos, se os atributos humanos são intrínsecos ou conclusivos, e a se natureza humana é boa, má ou neutra, preguiçosa ou trabalhadora (SCHEIN, 2009).

Apesar de que nem sempre sejam facilmente identificáveis, as ideias que orientam o que é "ser humano" são traduzidas segundo Silva (2001) de um modo explícito em comportamentos, práticas e políticas organizacionais. Desta forma, para o autor é importante ter conhecimento de como a organização conceitua o "ser humano", e consequentemente, as aplicações decorrentes destes significados atribuídos aos indivíduos no ambiente de trabalho. Corroborando com o exposto Wrightsman (1964, apud SILVA, 2001) desenvolveu seis dimensões referentes às crenças predominantes sobre as pessoas, denominadas "filosofias da natureza humana", que refletem o grau em que nós acreditamos que as pessoas: são leais ou desleais; são altruístas ou egoístas; são independentes e autossuficientes, ou dependentes e conformistas em relação a grupos ou figuras de autoridade; têm força de vontade e racionalidade, ou são controladas por forças interna ou externas irracionais; têm pensamentos, 
percepções e valores diversos, ou que têm basicamente as mesmas percepções, valores e assim por diante; são seres simples ou altamente complexos. No âmbito organizacional, as suposições básicas sobre natureza humana refletem em como os trabalhadores e gerentes são vistos (SCHEIN, 2009).

Por sua vez, a Natureza dos Relacionamentos Humanos é definida como a maneira das pessoas se relacionarem e a distribuição de poder (SCHEIN, 2009). Os pressupostos desta dimensão devem contemplar quatro aspectos básicos: identidade e papel; poder e influência; necessidade e metas; aceitação e intimidade (SCHEIN, 2009). Segundo Silva (2001) quando assumimos que os indivíduos são essencialmente agressivos em seus relacionamentos, por consequência a atitude é desenvolver uma sociedade em torno de controles, baseado em pressupostos que os indivíduos devem se cuidar e competir. Por outro lado, quando o entendimento é compartilhado, os indivíduos percebidos como essencialmente cooperativos, assim, os pressupostos podem enfatizar como se deve cooperar para que as metas e objetivos possam ser atingidos.

Estas duas naturezas apresentadas permitem uma melhor compreensão acerca do indivíduo e seus relacionamentos, sejam conscientes ou inconscientes, na instituição. E desta forma, também se pode conhecer alguns pressupostos que subsidiam as ações perpetradas pela organização em relação aos seus trabalhadores.

Para compreender o papel ou a importância do trabalhador na sua relação com a cultura organizacional, não é suficiente apenas verificar aspectos como a natureza e os relacionamentos humanos. É importante também compreender a cultura nacional, que influencia a cultura organizacional e as relações dentro da organização (MOTTA; CALDAS, 1997).

O Brasil é marcado por características peculiares em relação a sua cultura nacional, como por exemplo: impunidade (PRATES; BARROS, 1997; ALCADIPANI; CRUBELLATE, 2003), paternalismo (PRATES; BARROS, 1997; FREITAS, 2001; ALCADIPANI; CRUBELLATE, 2003), malandragem (FREITAS, 1997), centralização de poder (PRATES; BARROS, 1997; CARBONE, 2000; FREITAS, 2001), lealdade às pessoas (PRATES; BARROS, 1997; ALCADIPANI; CRUBELLATE, 2003); evitar conflitos (PRATES; BARROS, 1997; CARBONE, 2000); postura de espectador (PRATES; BARROS, 1997); levar vantagem (CARBONE, 2000). 
De fato, muitas das características da cultura brasileira estão presentes no serviço público, e consequentemente em muitas outras organizações públicas ou privadas, entre elas, em especial as universidade públicas, lócus de pesquisa deste artigo. Elas possuem estruturas complexas e altamente burocráticas tanto no âmbito administrativo quanto acadêmico, em decorrência disto, são lentas no atendimento pelo excesso de normas, e apresentam a eficiência comprometida devido as disfunções da burocracia (VIEIRA; VIEIRA, 2004). Rorato e Dias (2011) identificaram alguns traços culturais presente em uma universidade federal, típicos de uma organização pública brasileira, como: foco na eficiência em detrimento da eficácia dos serviços; estrutura gerencial centralizado; gestão que privilegia a burocracia por meio da racionalização estrutural e de cargos rigidamente descritos; e a impessoalidade nas relações. Estas características, segundo os autores, foram identificadas pelos servidores técnico-administrativos como elementos que resultam em limitações nos desafios profissionais e desenvolvimento de competências individual e coletivas, além de baixa flexibilidade gerencial e comprometimento com o trabalho.

Por sua vez, o corpo funcional da universidade - os servidores docentes e técnicoadministrativos, embora apresentem funções diferentes (atividades-fim e atividades-meio respectivamente) (UFSC, 1978), na comunidade interna e externa apresentam imagens diferentes (NUNES, 2011). Essas imagens serão explicitadas na seção que apresenta a análise dos dados obtidos durante a pesquisa.

\section{MÉTODO}

A presente pesquisa teve uma abordagem qualitativa e quantitativa, além de ser classificada como descritiva, e estudo de caso. A pesquisa buscou descrever a percepção dos servidores docentes e técnico-administrativos da Universidade Federal de Santa Catarina em relação a aspectos culturais como concepções sobre a natureza humana e relações no âmbito laboral.

Os dados foram coletados em dois momentos. Primeiramente, ocorreu o levantamento de dados quantitativos por meio da aplicação de um questionário online, divulgado pelo setor de divulgação da instituição e por e-mails dos servidores coletados nos sites dos cursos, departamentos, centros, secretarias e demais setores da instituição. A utilização de um instrumento online permitiu atingir aos pesquisados uma maior abrangência, bem como permite ao participante um completo anonimato - uma vez que não foi solicitado ao mesmo 
que se identificasse. O questionário foi respondido por 214 servidores. No segundo momento, em uma abordagem mais qualitativa, ocorreram 12 entrevistas individuais com os participantes que se disponibilizaram em descrever com maiores detalhes sobre o objeto alvo da pesquisa, e para tanto utilizou-se um roteiro semi-estrutrado para orientar a condução da mesma.

A partir da coleta dos dados obtidos no questionário online, o passo seguinte foi a análise e interpretação dos mesmos. Inicialmente, foram criados as categorias de análise: sobre cultura, que compreende a percepção dos participantes sobre valores, natureza e ações no trabalho do servidor docente e técnico-administrativo da UFSC; e Tipologia de relacionamento profissional, que compreende a percepção dos participantes sobre a natureza do relacionamento profissional entre os servidores e setores organizacionais. Os dados obtidos por meio do questionário online foram tratados seguindo uma abordagem de análise quantitativa, com a utilização de técnicas descritivas como distribuição de frequência. Por sua vez, as entrevistas foram analisadas por meio da análise de conteúdo, a qual permite ser aplicada tanto na pesquisa qualitativa quanto quantitativa (TRIVIÑOS, 1992).

Ademais, utilizou-se o método da triangulação, o qual compreende a combinação de técnicas quantitativas como o uso de questionário, técnicas qualitativas como as entrevistas, observações feita pelo pesquisador, e análise de literatura e documentos. Assim, a fraqueza de um único método será compensado pela força de outro (FLEURY; SHINYASHIKI; STEVANATO, 1997).

Para garantir e manter o anonimato os pesquisados foram identificados com a letra "P" seguidos de seus respectivos números (1 a 214) e os entrevistados foram identificados com a letra "E" de 1 a 12.

\section{ANÁLISE E INTERPRETAÇÃO DOS DADOS}

Antes de iniciar a apresentação dos dados provenientes desta pesquisa, é importante apresentar algumas informações sobre o lócus e os participantes da pesquisa. Mediante a Lei $\mathrm{n}^{\mathrm{o}}$ 3.849, pelo então presidente da República Juscelino Kubitschek foi criada em 18 de dezembro de 1960 a Universidade Federal de Santa Catarina (UFSC, 2010). A instituição Oferece 13 cursos de graduação na modalidade a distância, 105 presenciais, 29 de especialização, 61 de mestrado, 15 de mestrado profissional e 55 de doutorado (UFSC, 2015).

Para atender a esta demanda, até 2015 a instituição contava com um total de 2.285 
servidores docentes na educação superior, 113 educação básica destes e 235 docentes (UFSC, 2015). Por sua vez, em relação aos servidores técnico-administrativos a instituição conta com um total de 2.868, sendo 7\% de apoio, $64 \%$ de cargos de nível médio, e $28 \%$ superior (UFSC, 2015). Um fato a se destacar em relação aos servidores da organização, docentes e técnicoadministrativos, é que ao longo dos anos a titulação de ambos vem crescendo. No campo docente não é novidade, uma vez que existe a necessidade de alta titulação (doutorado) para o ingresso à carreira. No entanto, para os técnico-administrativos isso não é um requisito, ou seja, nos concursos mais recentes ingressam na instituição trabalhadores mais escolarizados para o trabalho, mesmo muitas vezes a função não exigindo tanta qualificação. Mas a carreira atualmente estimula.

Conforme explanado no método, a pesquisa teve um total de 214 respondentes do questionário online e 12 entrevistados. Desta forma, na Tabela 1 a seguir, são apresentados alguns dados representativos sobre a população pesquisada.

Tabela 1 Dados representativos dos participantes da pesquisa

\begin{tabular}{|ccc|}
\hline DADOS DOS PARTICIPANTES (RESUMO) - 214 & FREQ. & $\mathbf{\%}$ \\
\hline Gênero: Feminino & 114 & $\mathbf{5 3 , 3}$ \\
Idade média: 40 anos & - & - \\
\hline Formação: Pós-Graduação (Doutorado) & 56 & $\mathbf{2 6 , 2}$ \\
\hline Vinculo: Servidor Técnico-Administrativo & 116 & $\mathbf{5 4 , 2}$ \\
Tempo de Instituição: 1 a 5 anos & 106 & $\mathbf{4 9 , 5}$ \\
Regime de Trabalho: 40 horas & 109 & $\mathbf{5 0 , 9}$ \\
\hline Local de Vínculo: Centros de Ensino & 131 & $\mathbf{6 1 , 2}$ \\
\hline DADOS DOS ENTREVISTADOS (RESUMO) - 12 & \\
\hline Gênero: Feminino & 10 \\
\hline Faixa etária: 25 a 35 anos / 46 a 55 anos & $5 / 5$ \\
Formação: Pós-Graduação & 11 \\
\hline Vinculo: Servidor Docente / Servidor Técnico- \\
administrativo & $6 / 6$ \\
\hline Local de Vínculo: Centros de Ensino & 5 \\
\hline
\end{tabular}

Fonte: elaborado pelos autores (2016)

Após breve contextualização da instituição e dos participantes da pesquisa, parte-se agora para a apresentação dos dados obtidos por meio do questionário online e entrevistas. Para tanto, foram divididos em duas seções: caracterização dos servidores e tipologia de relacionamento profissional - as quais correspondem às categorias desta pesquisa. 


\subsection{CARACTERIZAÇÃO DOS SERVIDORES}

Nesta categoria é apresentada a percepção dos participantes sobre a natureza, os valores e as ações no trabalho do servidor docente e técnico-administrativo. Primeiramente, foi questionado sobre a natureza do servidor docente e do servidor técnico-administrativo. Tais naturezas refletem o grau em que acreditamos que as pessoas são altruístas ou egoístas, ativas ou preguiçosas, boas ou más, comprometidas ou descomprometidas, honestas ou desonestas, independente e autossuficientes ou dependentes e conformistas, leais ou desleais, racionais ou irracionais, simples ou complexas (SCHEIN, 2009; SILVA, 2001). A concepção de natureza humana reflete em como os trabalhadores são vistos pelos seus pares (SCHEIN, 2009), os quais são observados por meio dos seus comportamentos e práticas.

Tabela 2 Caracterização da natureza humana: servidores docentes

\begin{tabular}{|c|c|c|c|c|c|c|c|c|c|}
\hline NATUREZAS & & 1 & 2 & 3 & 4 & 5 & NATUREZAS & $\begin{array}{c}\text { EM } \\
\text { BRANCO }\end{array}$ & TOTAL \\
\hline \multirow{2}{*}{ Ativo } & Freq. & 36 & 60 & 72 & 32 & 5 & \multirow{2}{*}{ Preguiçoso } & 9 & 214 \\
\hline & $\%$ & 16,8 & 28,0 & 33,6 & 15,0 & 2,3 & & 4,2 & 100,0 \\
\hline \multirow{2}{*}{ Altruísta } & Freq. & 10 & 34 & 63 & 55 & 41 & \multirow{2}{*}{ Egoísta } & 11 & 214 \\
\hline & $\%$ & 4,7 & 15,9 & 29,4 & 25,7 & 19,2 & & 5,1 & 100,0 \\
\hline \multirow[b]{2}{*}{ Bom } & Freq. & 29 & 60 & 89 & 18 & 7 & \multirow{2}{*}{ Mau } & 11 & 214 \\
\hline & $\%$ & 13,6 & 28,0 & 41,6 & 8,4 & 3,3 & & 5,1 & 100,0 \\
\hline \multirow{2}{*}{ Comprometido } & Freq. & 28 & 71 & 70 & 29 & 5 & \multirow{2}{*}{ Descomprometido } & 11 & 214 \\
\hline & $\%$ & 13,1 & 33,2 & 32,7 & 13,6 & 2,3 & & 5,1 & 100,0 \\
\hline \multirow{2}{*}{ Honesto } & Freq. & 26 & 67 & 82 & 22 & 5 & \multirow{2}{*}{ Desonesto } & 12 & 214 \\
\hline & $\%$ & 12,1 & 31,3 & 38,3 & 10,3 & 2,3 & & 5,6 & 100,0 \\
\hline \multirow{2}{*}{$\begin{array}{l}\text { Independente e } \\
\text { autossuficiente }\end{array}$} & Freq. & 42 & 64 & 67 & 21 & 10 & \multirow{2}{*}{$\begin{array}{l}\text { Dependente e } \\
\text { conformista }\end{array}$} & 10 & 214 \\
\hline & $\%$ & 19,6 & 29,9 & 31,3 & 9,8 & 4,7 & & 4,7 & 100,0 \\
\hline \multirow{2}{*}{ Leal } & Freq. & 19 & 69 & 85 & 24 & 6 & \multirow{2}{*}{ Desleal } & 11 & 214 \\
\hline & $\%$ & 8,9 & 32,2 & 39,7 & 11,2 & 2,8 & & 5,1 & 100,0 \\
\hline \multirow{2}{*}{ Racional } & Freq. & 43 & 75 & 68 & 15 & 3 & \multirow{2}{*}{ Irracional } & 10 & 214 \\
\hline & $\%$ & 20,1 & 35,0 & 31,8 & 7,0 & 1,4 & & 4,7 & 100,0 \\
\hline \multirow{2}{*}{ Simples } & Freq. & 8 & 17 & 69 & 52 & 56 & \multirow{2}{*}{ Complexo } & 12 & 214 \\
\hline & $\%$ & 3,7 & 7,9 & 32,2 & 24,3 & 26,2 & & 5,6 & 100,0 \\
\hline
\end{tabular}

Fonte: dados primários (2016)

A caracterização da natureza dos servidores docentes está equilibrada segundo os respondentes da pesquisa; não apresenta disparidades fora dos pontos centrais. A caracterização está mais próxima das "boas" naturezas: ativo, altruísta, bom, comprometido, honesto, independente e autossuficiente, leal, racional, e complexo. Ressalta-se que a pesquisa foi respondida por mais servidores técnicos $(54,2 \%)$ do que servidores docentes $(45,8 \%)$, o que destaca a opinião positiva dos técnicos em relação aos docentes - e não se verifica a 
mesma positividade entre os docentes em relação a eles próprios. Contudo, existem algumas críticas sobre o comportamento docente dentro da instituição constantemente levantadas pelos participantes.

Os docentes aqui da UFSC, o que eu vou dizer. [...] muitas vezes a preocupação em desenvolver a carreira passando por cima das coisas que são importantes. Isso me preocupa bastante assim em relação os professores. Preocupação em pegar um projeto não para fazer uma coisa legal, uma coisa importante [...], que vai fazer um projeto de extensão, por exemplo, para comunidade, que vai dar uma visibilidade para UFSC no sentido de um espaço que acolhe a comunidade. Muitas vezes, o que está por trás disso, porque vai conseguir uma progressão. Isso me preocupa bastante. [...] E outra questão é assim, é que muitas vezes os professores assumem cargos de chefia, de gestão, sem estar muito preparado. Porque na UFSC não tem nem formação pra isso. [...] Não sou especialista para falar, mas tem que ser mediador, tem que ter outro tipo de comportamento que muitas vezes a pessoa assume o cargo e não tem a uma estabilidade com as pessoas, não tem a postura, não sabe lidar com as pessoas, não sabe fazer mediação, não sabe como se comportar ao chamar a pessoa pra conversar sobre algum problema, sobre alguma questão, a questão de avaliação também de avaliar os servidores, agentes técnicos sendo avaliados por um professor. E dai ele, geralmente esse professor não sabe do que se trata o cargo da pessoa, então quer cobrar coisas que não são da função da pessoa. E esse professor está ali e não quer nem saber o que é cada cargo dos técnicos para saber com quem pode contar cada coisa. E isso, isso é comum assim. Os professores assumir cargo de gestão, sem assumir ele integralmente. Integralmente no sentido de assumir uma outra postura, um outro modo de lidar com as pessoas (E11).

Existe na fala uma crítica explicita ao comportamento e posicionamento de alguns docentes em relação ao seu comprometimento com a comunidade externa, no sentido da realização de projetos, seja de pesquisa ou extensão, que em nada colaboram com a comunidade externa. Neste caso, o projeto tem como objetivo central a progressão do docente. Ademais, o entrevistado relata "muitas vezes eles assumem o projeto e não é ele quem coordena, só para ter o nome e conseguir a progressão. Muitas vezes pegam os técnicos para trabalhar juntos nos projetos para conseguir tocar sem ele ter que participar [...]" (E11). Neste ponto, não somente técnicos, mas próprios orientandos e acadêmicos.

Uma outra crítica realizada é o trabalhador assumir um cargo de direção e não ter conhecimento de gestão/administração, das atividades desenvolvidas por este setor, nem as atribuições de seu cargo e dos demais - que ocorre na instituição (CUNHA, 2016). Neste caso, além destes aspectos, a crítica foca no comportamento do chefe em relação aos membros da equipe, na qual ele ressalta que o chefe deve ser também um mediador e saber como se relacionar com os demais servidores.

De fato, a maioria das críticas em relação aos docentes estão vinculadas a sua relação 
com os demais técnicos e docentes e também nos aspectos de gestão - ou seja, as ações no trabalho. Pouco é comentado sobre o seu desempenho dentro da parte de ensino, mesmo porque, neste caso, os principais "clientes" seriam os discentes - que não foram alvo desta pesquisa. Ademais, é nos aspectos relacionais e de gestão em que os problemas se configuram com maior frequência - seja em relação aos docentes ou aos técnicos.

Não se trata de generalizar os comportamentos dos docentes; existem, necessariamente, servidores que trabalham em uma perspectiva de racionalidade instrumental, voltados para os objetivos fins sem se preocuparem com os meios para alcançá-lo (RAMOS, 1989), tendo assim uma natureza de homem econômico, motivados basicamente por incentivos financeiros. Desta forma, para se ter sucesso nesse tipo de sociedade, de acordo com suas regras de recompensa e castigo, o indivíduo tem que ser programado como um ser econômico, ou seja, deve ser funcional - seguindo uma racionalidade instrumental (RAMOS, 1989). Outra forma de classificar determinados comportamentos, é por meio da dimensão individualista de Hofstede ([19--]a; [19--]b), em que o indivíduo tende a agir e a se comportar de acordo com atividades que lhe proporcionarão ganhos pessoais e satisfação de seus desejos.

Por sua vez, a caracterização da natureza dos servidores técnico-administrativos apresenta alguns pontos de destaque, conforme pode ser visualizado na Tabela 3 a seguir.

Tabela 3 Caracterização da natureza humana: servidores técnico-administrativos

\begin{tabular}{|c|c|c|c|c|c|c|c|c|c|}
\hline NATUREZAS & & 1 & 2 & 3 & 4 & 5 & NATUREZAS & $\begin{array}{c}\text { EM } \\
\text { BRANCO }\end{array}$ & TOTAL \\
\hline Ativo & $\begin{array}{c}\text { Freq. } \\
\%\end{array}$ & $\begin{array}{c}6 \\
2,8\end{array}$ & $\begin{array}{l}14 \\
6,5\end{array}$ & $\begin{array}{c}33 \\
15,4\end{array}$ & $\begin{array}{c}72 \\
33,6\end{array}$ & $\begin{array}{c}79 \\
36,9\end{array}$ & Preguiçoso & $\begin{array}{l}10 \\
4,7\end{array}$ & $\begin{array}{c}214 \\
100,0\end{array}$ \\
\hline Altruísta & $\begin{array}{c}\text { Freq. } \\
\%\end{array}$ & $\begin{array}{c}9 \\
4,2\end{array}$ & $\begin{array}{c}29 \\
13,6\end{array}$ & $\begin{array}{c}86 \\
40,2\end{array}$ & $\begin{array}{c}37 \\
17,3\end{array}$ & $\begin{array}{c}44 \\
20,6\end{array}$ & Egoísta & $\begin{array}{c}9 \\
4,2\end{array}$ & $\begin{array}{c}214 \\
100,0\end{array}$ \\
\hline Bom & $\begin{array}{c}\text { Freq. } \\
\%\end{array}$ & $\begin{array}{l}17 \\
7,9\end{array}$ & $\begin{array}{c}46 \\
21,5\end{array}$ & $\begin{array}{c}94 \\
43,9\end{array}$ & $\begin{array}{c}23 \\
10,7\end{array}$ & $\begin{array}{c}24 \\
11,2\end{array}$ & Mau & $\begin{array}{l}10 \\
4,7\end{array}$ & $\begin{array}{c}214 \\
100,0\end{array}$ \\
\hline Comprometido & $\begin{array}{c}\text { Freq. } \\
\%\end{array}$ & $\begin{array}{c}6 \\
2,8\end{array}$ & $\begin{array}{c}25 \\
11,7\end{array}$ & $\begin{array}{c}45 \\
21,0\end{array}$ & $\begin{array}{c}68 \\
31,8\end{array}$ & $\begin{array}{c}61 \\
28,5\end{array}$ & Descomprometido & $\begin{array}{c}9 \\
4,2\end{array}$ & $\begin{array}{c}214 \\
100,0\end{array}$ \\
\hline Honesto & $\begin{array}{c}\text { Freq. } \\
\%\end{array}$ & $\begin{array}{l}21 \\
9,8\end{array}$ & $\begin{array}{c}53 \\
24,8\end{array}$ & $\begin{array}{c}78 \\
36,4\end{array}$ & $\begin{array}{c}25 \\
11,7\end{array}$ & $\begin{array}{c}27 \\
12,6\end{array}$ & Desonesto & $\begin{array}{l}10 \\
4,7\end{array}$ & $\begin{array}{c}214 \\
100,0\end{array}$ \\
\hline $\begin{array}{l}\text { Independente e } \\
\text { autossuficiente }\end{array}$ & $\begin{array}{c}\text { Freq. } \\
\%\end{array}$ & $\begin{array}{c}7 \\
3,3\end{array}$ & $\begin{array}{l}16 \\
7,5\end{array}$ & $\begin{array}{c}48 \\
22,4\end{array}$ & $\begin{array}{c}72 \\
33,6\end{array}$ & $\begin{array}{c}61 \\
28,5\end{array}$ & $\begin{array}{l}\text { Dependente e } \\
\text { conformista }\end{array}$ & $\begin{array}{l}10 \\
4,7\end{array}$ & $\begin{array}{c}214 \\
100,0\end{array}$ \\
\hline Leal & $\begin{array}{c}\text { Freq. } \\
\%\end{array}$ & $\begin{array}{l}14 \\
6,5\end{array}$ & $\begin{array}{c}41 \\
19,2\end{array}$ & $\begin{array}{c}84 \\
39,3\end{array}$ & $\begin{array}{c}36 \\
16,8\end{array}$ & $\begin{array}{c}29 \\
13,6\end{array}$ & Desleal & $\begin{array}{l}10 \\
4,7\end{array}$ & $\begin{array}{c}214 \\
100,0\end{array}$ \\
\hline Racional & $\begin{array}{c}\text { Freq. } \\
\%\end{array}$ & $\begin{array}{c}9 \\
4,2\end{array}$ & $\begin{array}{c}35 \\
16,4\end{array}$ & $\begin{array}{c}86 \\
40,2\end{array}$ & $\begin{array}{c}45 \\
21,0\end{array}$ & $\begin{array}{c}29 \\
13,6\end{array}$ & Irracional & $\begin{array}{l}10 \\
4,7\end{array}$ & $\begin{array}{c}214 \\
100,0\end{array}$ \\
\hline Simples & $\begin{array}{c}\text { Freq. } \\
\%\end{array}$ & $\begin{array}{c}25 \\
11,7\end{array}$ & $\begin{array}{c}46 \\
21,5\end{array}$ & $\begin{array}{c}79 \\
36,9\end{array}$ & $\begin{array}{l}20 \\
9,3\end{array}$ & $\begin{array}{c}34 \\
15,9\end{array}$ & Complexo & $\begin{array}{l}10 \\
4,7\end{array}$ & $\begin{array}{c}214 \\
100,0\end{array}$ \\
\hline
\end{tabular}

Fonte: dados primários (2016) 
Um pouco diferente da caracterização dos servidores docentes, os técnicoadministrativos estão mais próximos de algumas das naturezas "negativas": preguiçoso, egoísta, descomprometido, dependente e conformista, desleal, irracional, e simples. Em especial, o item preguiçoso e descomprometido está mais ressaltado nas respostas. Esta visão sobre os servidores técnico-administrativos não é algo apenas presente na UFSC, mas nas repartições públicas brasileiras (PIRES; MACÊDO, 2006) e talvez até internacionais. As quais estes são vistos como trabalhadores que não ociosos, preguiçosos e descomprometidos com o trabalho. Essas características podem ser identificadas como na natureza da atividade humana de Schein (2009), a qual na orientação de ser, identifica o indivíduo como reativo, passivo e que aceita a realidade como ela é posta. Em uma outra perspectiva, pode-se inferir que a percepção sobre o servidor técnico-administrativo pode ser rotulada na Teoria $X$ de McGregor (1960) ao afirmar que as pessoas não gostam de trabalhar, falta-lhes ambição, são irresponsáveis e preferem receber ordens.

E dos TAES eu vejo assim, todo mundo que eu tive contato pra trabalhar tal, volto a dizer, talvez por eu ter trabalhado muito tempo no privado, que existe muita acomodação né. Tipo "ah, eu não sei", ai chegou um aluno na frente da secretaria "ah eu não sei" e não vai procurar saber e não vai responder a dúvida do aluno e não vai não sei o que, ou que faltam demais, ou que fazem um horário. Acho que tem bastante comodismo assim. É ruim pensar porque a gente fica falando "ah porque o trabalho público é assim mesmo", mas não é, eu acho que tem uma galera assim, tanto de mais velhos quanto de mais novos, que cumprem bem a sua função, que são excelentes e tudo mais. Mas que, no geral, acho que é bem acomodado. Então eu acho que às vezes tem bastante comodismo, mas não é geral (E9).

No geral, existe uma minoria que detona, porque eu sempre falo: a pior categoria é a nossa, a mais sem vergonha é a nossa: servidor técnico. Porque assim, do docente, quando pega pra capar, por mais que sejam desunidos, eles se unem. Na nossa categoria não, entendesse? Assim como tem na categoria deles um querendo comer o outro, também tem na nossa. Então eu acho assim que a nossa categoria poderia ser mais unida e eu deixo bem claro $[\ldots](\mathrm{E} 5)$.

Existe esta visão "negativa" tanto de docentes, conforme primeira verbalização, quanto de técnicos. Estas e outras verbalizações vêm a confirmar o que os dados demonstraram na tabela anterior, a visão negativa que muitos têm sobre os servidores técnico-administrativos. Inclusive, a própria desunião entre a categoria, que muitas vezes é motivada por aspectos políticos, interesses individuais ou de determinados grupos ou até mesmo passiva/desmotivada. 
De fato existe uma diferenciação entre os docentes e técnico-administrativos no que tange ao seu trabalho, pois são de naturezas de atividades e realidades diferentes. Como por exemplo, a integração do ensino, pesquisa e extensão, muito mais forte com os servidores docentes. Por sua vez, "no pessoal técnico-administrativo eu vejo também lá pelo próprio [SETOR DE TRABALHO], eu vejo às vezes até uma certa resistência com relação a abertura para o ensino e pesquisa" (E7). Tal abertura se configura não apenas no desejo e interesse (ou não) dos técnicos em desenvolverem este tipo de atividade, mas na própria abertura da instituição para que os mesmos desenvolvam.

Apesar de o campo docente e técnico serem duas carreiras diferentes, com suas especificidades, em geral, pode-se afirmar que os docentes tem muito mais oportunidades que os técnicos: "Acho que o professor tem muito mais oportunidades, ele tem mais acesso, mais oportunidades, ele consegue o reconhecimento que muitas vezes o técnico-administrativo não consegue ou não tem essa mesma oportunidade, ou às vezes também não busca" (E8). Para o entrevistado muitas vezes essa falta de oportunidade se encontra mais no comodismo do trabalhador, que não se organiza e planeja para realizar determinadas atividades, e assim, não busca, por exemplo, uma licença para realizar um mestrado ou doutorado.

Ao discutir sobre a próatividade e o comodismo, outros relatos ressaltam uma diferenciação entre os trabalhadores mais antigos e os mais novos. No caso dos docentes, "o que eu vejo é que os professores quanto mais antigos, não é regra, mas eles tem mais vícios, tanto do "eu vou fazer o que eu quiser. Eu vou dar quantas aulas eu quiser e coisas assim"” (E9). Por sua vez, os "[...] mais novos estão mais ativos, tanto professores quanto técnicos. Não sei também se é uma coisa do momento, 'estamos felizes porque passamos e agora a gente vai dar o sangue’. Mas não precisa dar o sangue, pode só fazer o que tu tem que fazer, já tá ótimo" (E9). Por estarem há mais tempo na instituição muitos servidores interpretam e executam suas atividades seguindo um princípio de tradição, ou seja, realizam como sempre fizeram (SCHEIN, 2009).

De fato os argumentos dos pesquisados e entrevistados relatam muito sobre a próatividade de alguns trabalhadores novos, que entram na instituição com energia para realizar mudanças e melhorar a instituição.

Os técnicos agora que estão entrando nos concursos, nos últimos 10 anos assim, estão vindo com uma postura mais de querer se colocar, de ganhar espaço, de querer participar de colegiado, de querer participar de reunião, de querer participar em projeto. Muitos projetos na UFSC os técnicos não 
podem coordenar, não sei porque. [...] Estão tentando um espaço tanto com os gestores quanto também com esses técnicos mais antigos, querendo espaço, de colocar que chegou e que respeita o que foi construído até agora, mas também quer se colocar. Tem condições, tem capacidade de assumir projetos, tem capacidade de assumir chefias, tem capacidade de fazer as coisas. E tem aquilo que eu te falei, os técnicos estão vindo com a formação com nível superior ao que é exigido pelo cargo, então vem com tudo (E11).

A verbalização apresenta a fala sobre os técnicos, mas, necessariamente, também existem docentes que se inserem neste contexto. Ao contrário da perspectiva da Teoria $\mathrm{X}$, a Teoria Y de McGregor pressupõe que os indivíduos desejam trabalhar, aceitam responsabilidade, são auto gerenciáveis e criativos (MCGREGOR, 1960), como se verifica na verbalização. Em realidade existem tanto funcionários "bons" quanto "ruins", sejam eles novos ou antigos, "nós temos excelentes funcionários e nós temos excelentes professores, mas nesse meio de excelentes têm alguns perdidos que não querem nada com nada [...]" (E5). Ou seja, existem aqueles que querem contribuir e aqueles que não querem contribuir.

Existem alguns privilegiados que podem tudo. Outros devem tudo. Existem aqueles que trabalham somente pensando no seu bolso e outros pensando na sociedade (P79).

O que eu vejo como um lado negativo, que infelizmente é mais regra do que exceção também em outras universidades, é que a integração entre técnicos e professores não é tão estreita como poderia, e no meu ponto de vista deveria ser. Parece que são duas categorias a parte, e que muitas vezes parece que nem trabalham na mesma instituição. [...] Então eu acho que todos nós somos, na verdade somos funcionários da universidade. Temos funções diferentes, mas todos pertencemos ao quadro de funcionários da mesma instituição. Então nós trabalhamos pelo mesmo fim, de formas diferentes, mas nosso objetivo final é o mesmo. E muitas vezes por questões, talvez até políticas, as carreiras são diferentes, as pessoas acabam se distanciando mais do que deveriam (E1).

Eu conheço muitos professores, muitos técnicos, com tantos anos de casa, e o que eu posso dizer é isso. Aqueles que querem construir e aqueles que não querem construir. Aqueles que são comprometidos e aqueles que não são comprometidos. Aqueles que colocam o interesse coletivo ou organizacional, e aqueles que colocam seus interesses particulares ou não estão interessados na organização (E3).

Eu prefiro não pensar em corpo docente e corpo técnico administrativo. Eu penso que existem pessoas que estão motivadas, que têm interesse de fazer as coisas acontecerem e tem outras que não. Tem uns que são pró ativos e tem uns que não são pró ativos, independente deles fazerem parte do corpo docente ou do corpo técnico-administrativo. É a minha percepção (E10). 
Por fim, os valores, a natureza e as ações do trabalho dependem de cada um. Os dados apresentados nesta seção relatam a visão dos próprios trabalhadores sobre eles mesmos e seus pares, são relatos sobre algumas situações observáveis no cotidiano institucional e que repercutem tanto positivamente quanto negativamente. Em sequência é desenvolvido mais sobre os relacionamentos profissionais dos servidores e entre eles e setores organizacionais.

\subsection{TIPOLOGIA DE RELACIONAMENTO PROFISSIONAL}

Após a caracterização dos servidores docentes e técnico-administrativos em relação a sua natureza, valores e ações no trabalho, parte-se para a caracterização da natureza do relacionamento profissional entre os servidores e setores organizacionais. Desta forma, compreende-se como ocorre esta relação a partir dos relatos dos pesquisados.

Primeiramente, foi questionado aos participantes como eles caracterizavam o relacionamento profissional entre chefias e subordinados no seu setor e na UFSC, docentes e técnico-administrativos no seu setor e na UFSC, entre chefias no seu setor e na UFSC, entre docentes no seu setor e na UFSC, entre técnico-administrativos no seu setor e na UFSC, entre os profissionais de setores distintos da UFSC (Centros de Ensino, Departamentos, PróReitorias, Secretarias, HU, etc.). Os dados podem ser visualizados na Tabela 4 em sequência.

Tabela 4 Caracterização do relacionamento profissional

\begin{tabular}{|c|c|c|c|c|c|c|c|c|}
\hline & & $\begin{array}{c}\text { Muito } \\
\text { Amigável }\end{array}$ & Amigável & $\begin{array}{c}\text { Neutro - } \\
\text { Indiferente }\end{array}$ & Conflituoso & $\begin{array}{c}\text { Muito } \\
\text { Conflituoso } \\
\end{array}$ & $\begin{array}{c}\text { Em } \\
\text { Branco } \\
\end{array}$ & TOTAL \\
\hline Chefias e & Freq. & 42 & 100 & 28 & 24 & 13 & 7 & 214 \\
\hline $\begin{array}{l}\text { Subordinados no } \\
\text { seu setor }\end{array}$ & $\%$ & 19,6 & 46,7 & 13,1 & 11,2 & 6,1 & 3,3 & 100,0 \\
\hline Chefias e & Freq. & 3 & 59 & 78 & 61 & 6 & 7 & 214 \\
\hline $\begin{array}{c}\text { Subordinados na } \\
\text { UFSC }\end{array}$ & $\%$ & 1,4 & 27,6 & 36,4 & 28,5 & 2,8 & 3,3 & 100,0 \\
\hline $\begin{array}{l}\text { Docentes e } \\
\text { Técnico- }\end{array}$ & Freq. & 23 & 93 & 54 & 32 & 5 & 7 & 214 \\
\hline $\begin{array}{c}\text { administrativos no } \\
\text { seu setor }\end{array}$ & $\%$ & 10,7 & 43,5 & 25,2 & 15,0 & 2,3 & 3,3 & 100,0 \\
\hline $\begin{array}{l}\text { Docentes e } \\
\text { Técnico- }\end{array}$ & Freq. & 3 & 52 & 69 & 66 & 17 & 7 & 214 \\
\hline $\begin{array}{c}\text { administrativos na } \\
\text { UFSC }\end{array}$ & $\%$ & 1,4 & 24,3 & 32,2 & 30,8 & 7,9 & 3,3 & 100,0 \\
\hline $\begin{array}{c}\text { Entre Chefias no } \\
\text { seu setor }\end{array}$ & $\begin{array}{l}\text { Freq. } \\
\%\end{array}$ & $\begin{array}{c}24 \\
11,2\end{array}$ & $\begin{array}{l}113 \\
52,8\end{array}$ & $\begin{array}{c}42 \\
19,6\end{array}$ & $\begin{array}{c}23 \\
10,7\end{array}$ & $\begin{array}{c}5 \\
2,3\end{array}$ & $\begin{array}{c}7 \\
3,3\end{array}$ & $\begin{array}{c}214 \\
100,0\end{array}$ \\
\hline $\begin{array}{c}\text { Entre Chefias na } \\
\text { UFSC }\end{array}$ & $\begin{array}{l}\text { Freq. } \\
\%\end{array}$ & $\begin{array}{c}3 \\
1,4\end{array}$ & $\begin{array}{c}75 \\
35,0\end{array}$ & $\begin{array}{c}81 \\
37,9\end{array}$ & $\begin{array}{c}42 \\
19,6\end{array}$ & $\begin{array}{c}6 \\
2,8\end{array}$ & $\begin{array}{c}7 \\
3,3\end{array}$ & $\begin{array}{c}214 \\
100,0\end{array}$ \\
\hline $\begin{array}{c}\text { Entre Docentes no } \\
\text { seu setor }\end{array}$ & $\begin{array}{l}\text { Freq. } \\
\%\end{array}$ & $\begin{array}{c}24 \\
11,2\end{array}$ & $\begin{array}{c}76 \\
35,5\end{array}$ & $\begin{array}{c}52 \\
24,3\end{array}$ & $\begin{array}{c}45 \\
21,0\end{array}$ & $\begin{array}{l}10 \\
4,7\end{array}$ & $\begin{array}{c}7 \\
3,3\end{array}$ & $\begin{array}{c}214 \\
100,0\end{array}$ \\
\hline
\end{tabular}




\begin{tabular}{|c|c|c|c|c|c|c|c|c|}
\hline & & $\begin{array}{c}\text { Muito } \\
\text { Amigável }\end{array}$ & Amigável & $\begin{array}{c}\text { Neutro - } \\
\text { Indiferente }\end{array}$ & Conflituoso & $\begin{array}{c}\text { Muito } \\
\text { Conflituoso } \\
\end{array}$ & $\begin{array}{c}\text { Em } \\
\text { Branco } \\
\end{array}$ & TOTAL \\
\hline \multirow{2}{*}{$\begin{array}{c}\text { Entre Docentes na } \\
\text { UFSC }\end{array}$} & Freq. & 3 & 71 & 76 & 50 & 6 & 8 & 214 \\
\hline & $\%$ & 1,4 & 33,2 & 35,5 & 23,4 & 2,8 & 3,7 & 100,0 \\
\hline \multirow{2}{*}{$\begin{array}{c}\text { Entre Técnico- } \\
\text { administrativos no } \\
\text { seu setor }\end{array}$} & Freq. & 42 & 109 & 30 & 24 & 2 & 7 & 214 \\
\hline & $\%$ & 19,6 & 50,9 & 14,0 & 11,2 & 0,9 & 3,3 & 100,0 \\
\hline \multirow{2}{*}{$\begin{array}{c}\text { Entre Técnico- } \\
\text { administrativos na } \\
\text { UFSC }\end{array}$} & Freq. & 6 & 102 & 67 & 29 & 2 & 8 & 214 \\
\hline & $\%$ & 2,8 & 47,7 & 31,3 & 13,6 & 0,9 & 3,7 & 100,0 \\
\hline $\begin{array}{c}\text { Entre os } \\
\text { Profissionais de }\end{array}$ & Freq. & 2 & 71 & 91 & 38 & 5 & 7 & 214 \\
\hline $\begin{array}{c}\text { Setores distintos da } \\
\text { UFSC }\end{array}$ & $\%$ & 0,9 & 33,2 & 42,5 & 17,8 & 2,3 & 3,3 & 100,0 \\
\hline
\end{tabular}

Fonte: dados primários (2016)

Em geral os relacionamentos profissionais nos setores são mais amigáveis do que comparados na UFSC. Já no âmbito da instituição, alguns índices apresentam uma tendência para relacionamentos de neutro/indiferente para conflituosos, como é o caso entre chefias e subordinados, e docentes e técnicos. Fatos já constatados nos discursos dos pesquisados, e que voltam a ser repetidos.

O Entrevistado 3 apresenta uma questão de conflito entre servidores antigos e novos. Apesar do ingresso de diversos novos trabalhadores qualificados na instituição, com graduação e pós-graduação, os mesmos, segundo ele, não possuem um conhecimento da organização, e ao assumirem, muitas vezes, algum cargo de chefia, acabam impondo sua forma de gestão, "E ai eles trazem uma visão completamente de fora, e impõem para um grupo que construiu a instituição. Acho isso uma maldade sabe, uma maldade tamanha. E isso foi feito na instituição toda" (E3). Em outras palavras, "a atual gestão colocou em cargos de chefia servidores que não têm conhecimento organizacional para a função. Isto ocasionou muito conflito entre servidores antigos e novos" (P32). Em alguns momentos os trabalhadores mais antigos se sentem "julgados" pelos mais novos, como se não estivessem contribuído para a instituição, "Os técnicos mais antigos se sentem assim 'pô, está vindo, trazendo coisa nova, e tão dizendo que, que até agora o que eu estava fazendo não serve mais?" (E11). Ou "Hoje os antigos estão encontrando algumas dificuldades, porque a UFSC está com um cenário novo, pessoas novas entrando, as informações hoje estão um pouco mais restritas por insegurança dos novos diante do cenário que a UFSC está passando, muita pressão, etc." (P97).

Por outro lado, existe também a visão dos novos que relatam o comodismo dos mais 
antigos para mudanças, na famosa frase "deixa como está" ou "sempre foi feito dessa maneira". E também "acabam tendo essa reação dos antigos, e se sentem que não estão sendo acolhidos, que não estão sendo aceitos e valorizados" (E11). Do mesmo modo, "quem tá lá dentro já se conhecem melhor porque trabalham há 30 anos ou mais, mas principalmente quando tu chega novo, os outros não te dão muita abertura" (E8). Ou seja, existem duas visões sobre esta situação dos trabalhadores antigos e novos, e um conflito que perdura há muito tempo segundo os participantes. Há por um lado nos novos (progresso e progressistas) e por outro os antigos (resistência e conservadores), os quais concomitantemente são poderes concorrentes e complementares (BOURDIEU, 2013).

Ao tratar sobre a categoria docente, uma das situações mais levantadas pelos pesquisados sobre o relacionamento profissional conflituoso entre eles é: "a competição por bolsas produtividade" (P3), a "disputa por espaços, principalmente com relação às pesquisas, com corrida para quem publica mais" (P64); "quando envolve dinheiro em consultorias um quer comer o outro, as vezes se tornam inimigos declarados. Competitividade negativa, tudo por dinheiro" (P71). Nesta perspectiva, "enquanto estivermos centrado na cultura da competição e da produtividade acadêmica, um vai sempre querer matar o outro para aparecer em face dos parcos recursos existentes" (P10). Isto implica enfatizar que, "toda a dinâmica institucional reforça o individualismo, a competição e a desonestidade, e a pior de tudo é quando acontece de forma velada. É uma instituição em que não se pode confiar em ninguém" (P10).

\begin{abstract}
A pressão para produzir artigos, participar de seminários e congressos, ter horários irregulares quanto as suas disciplinas, enfim, poderíamos dizer que ultrapassar a meta é constante. Não importa se para isso os docentes sangrem aos sábados e domingos em seus computadores. Importa a voracidade do lattes(fundio) e capes(talização). Nosso mercado singular, que via política do medo e intolerância atinge a todos em busca continua de nobreza ou excelência acadêmica. Nesse contexto surge um novo tipo de docente que passa a ser valorizado não somente pela sua competência, mas capacidade de adesão incondicional. Esse sujeito com medos, que realiza tarefas dobradas, está à disposição fulltime na universidade, concorre com seu par em produtividade. Que os levam a certas práticas indesejáveis com seus parceiros e pares, que transforma muitos em reprodutores do discurso dominante, apesar de seu discurso moralizante (informação verbal ${ }^{1}$ ).
\end{abstract}

\footnotetext{
${ }^{1}$ Informação verbal: comentário realizado pela professora Dra. Margarida Barreto em qualificação de projeto de tese ocorrido em 20 de agosto de 2014.
} 
Devido a ênfase na condução de pesquisas, critérios de avaliação de produtividade e qualidade, os docentes concentram-se em suas atividades, em geral, na produção acadêmica. $\mathrm{Ou}$ seja, as publicações, os projetos, os procedimentos de internacionalização e outras atividades inseridas no lattes podem significar a diferença acadêmica entre ele e outros colegas na aprovação de projetos ou bolsas de produtividade (CARAN, 2007; NUNES, 2011).

Existem necessariamente conflitos dentro do ambiente de trabalho, o que são perfeitamente normais - no sentido de uma discussão sobre determinado tema ou atividade, e não uma questão de violência. Para alguns, essas questões de diferenças são trabalhadas com bastante civilidade. No entanto, há situações que necessitam de maior "pulso" por parte dos superiores para que elas não se repitam, não desgastem toda a equipe e provoquem um clima desagradável, "[...] eu gostaria que muitas vezes a gestão tivesse um pouco mais de pulso até para conduzir algumas discussões, para evitar perda de tempo e aquelas discussões externas, redundantes, circulares que a gente fica horas e horas numa reunião e não sai do lugar" (E1).

De certa forma existe uma diferenciação entre chefe e subordinado. Um dos entrevistados ao sair da posição de subordinado e ser nomeado com uma chefia, sentiu a diferença de comportamento entre os pares: "[...] eu senti uma diferença de comportamento dos meus pares, não todos, algumas pessoas continuaram normal, mas de outras assim eu senti um pouco esse distanciamento, de um olhar diferente" (E7). O simples fato desta pessoa ser nomeada para um cargo de chefia, já fez com que seus pares alterassem seu comportamento com ela, criando assim uma distância. E tal distancia, entre chefe e subordinado, ela também visualiza no seu superior "E com relação a nossa chefia mesmo é uma distância assim, abismal. Pela própria forma como ele atua, de inibição. Em alguns momentos ele até se coloca como estar perto, tenta fazer essa coisa de ser o chefe amigo, mas não é" (E7). Ou seja, são situações criadas pelo próprio ocupante do cargo de chefia, mas também influenciadas por aqueles que estão nesta posição e pelos próprios subordinados que "permitem" ou ficam acomodados com este distanciamento.

Muitos dos relacionamentos dentro de qualquer instituição são "diplomáticos", " $E$ basicamente polido, basicamente na base da educação, do respeito mútuo. [...] No nosso departamento eu vejo isso. As pessoas são polidas, são educadas, entretanto, não necessariamente elas são justas ou são corretas, basicamente isso" (E10). De fato muitos dos relacionamentos são profissionais, com sinais de educação e coleguismo entre as partes, 
principalmente se os mesmos forem do mesmo grupo dominante. Há discursos que enfatizam a falta de uma política ou ações de integração: "Falta uma política de integração entre os vários setores, vários segmentos, e a administração central" (P78); "Falta integração. A UFSC deveria promover encontros, reuniões, seminários entre os diferentes grupos" (P48).

Enfim, os dados não demonstram nem que existe um comportamento amigável nem conflituoso, mas a preponderância de aspectos neutros de relacionamento profissional. Por um lado, nos setores o clima é mais amigável, já na instituição tende a ser menos amigável entre chefias e subordinados, e técnicos e docentes.

\section{CONSIDERAÇÕES FINAIS}

Este artigo teve por objetivo descrever a percepção dos servidores docentes e técnicoadministrativos da Universidade Federal de Santa Catarina em relação a aspectos culturais como concepções sobre a natureza humana e relacionamento profissional no âmbito laboral. Por meio das categorias de análise foi possível desmitificar sobre os valores, a natureza e as ações no trabalho daqueles que movem a instituição e são elementos fundamentais na criação e prática da cultura organizacional.

$\mathrm{Na}$ primeira categoria, sobre a caracterização de natureza humana preponderante entre os servidores, foi observado um perfil mais "positivo" dos trabalhadores docentes, embora existam críticas e preocupações pois os mesmos muitas vezes atuam conforme seus próprios interesses e desconhecem como gestionar. E uma tendência de neutro a "negativo" para os trabalhadores técnico-administrativos, vistos como preguiçosos e descomprometidos com o trabalho, tanto por docentes quanto por técnicos. Características estas indiscutivelmente atribuídas a estes trabalhadores pela sociedade brasileira a funcionários públicos. Ou seja, os servidores técnicos já tem uma "má fama" nacional, e pode-se complementar que em determinadas circunstancias podem sofrer de violências e até assédio moral por isto. A realidade é que existem tanto trabalhadores comprometidos com o trabalho e com os objetivos institucionais quanto trabalhadores descomprometidos e que visam seus próprios interesses.

$\mathrm{Na}$ categoria em sequência, foi caracterizado o relacionamento profissional, no sentido de identificar se é amigável, neutro/indiferente, ou conflituoso. Pelos dados é possível observar que o relacionamento profissional nos setores tende mais para o amigável, ao contrário da UFSC que em determinadas instancias tende para o conflituoso. Ademais, existem situações de conflito que perduram há tempos, como situações entre docentes e 
técnicos, trabalhadores novos e antigos, e chefes e subordinados. Conjunturas estas que reforçam um problema existente na instituição ao longo de sua história.

Muitas destas situações que perduram ao longo do tempo na instituição, são ainda vivenciadas e praticadas na mesma. Algumas destas repercutem negativamente no dia-a-dia laboral e influenciam os comportamentos e práticas organizacionais, além de afetarem os próprios trabalhadores e a imagem destes perante a comunidade interna e a sociedade. Portanto, se faz necessário que os próprios servidores e principalmente a instituição tentem diminuir a avaliação negativa destes trabalhadores dentro e fora da comunidade acadêmica, além de tentar desenvolver mecanismos que amenizem a tensão nas relações entre estes de modo a garantir maior efetividade das atividades desenvolvidas.

\section{REFERENNCIAS}

ALCADIPANI, R.; CRUBELLATE, J. M. Cultura organizacional: generalizações improváveis e conceituações imprecisas. Revista de Administração de Empresas, São Paulo, v. 43, n. 2, p. 64-77, 2003.

BOURDIEU, P. Homo academicus. 2. ed. Florianópolis: ed. da UFSC, 2013.

CARAN, Vânia Cláudia Spoti. Riscos Psicossociais e Assédio Moral no Contexto Acadêmico. 2007. 188f. Dissertação (Mestrado em Enfermagem) - Programa de PósGraduação em Enfermagem Fundamental, Universidade de São Paulo, São Paulo, 2007.

CARBONE, P. Cultura organizacional do setor público brasileiro: desenvolvimento de uma metodologia de gerenciamento da cultura. Revista de Administração Pública, v. 34, n. 2, 2000 .

CUNHA, J. P. Análise do processo de socialização de novos servidores técnicoadministrativos em educação da UFSC. 2016. 247 p. Dissertação (Mestrado) - Programa de Pós-Graduação - Mestrado Profissional em Administração Universitária, Centro SócioEconômico. Universidade Federal de Santa Catarina. Florianópolis, 2016.

FLEURY, M. T. L. Estória, mitos, heróis: cultura organizacional e relações de trabalho. Revista de Administração de Empresa - RAE. Rio de Janeiro, v. 27, n. 4, p. 7-18, 1987.

FLEURY, M. T. L. O desvendar a cultura de uma organização - uma discussão metodológica. In: FLEURY, M. T. L.; FISCHER, R. M. (Coords). Cultura e poder nas organizações. 2.ed. São Paulo: Atlas, 1996. p. 15-27.

FLEURY, M. T. L.; SHINYASHIKI, G. T.; STEVANATO, L. A. Arqueologia teórica e dilemas metodológicos dos estudos sobre cultura organizacional. In: MOTTA, F. C. P.; CALDAS, M. P. (Org.). Cultura organizacional e cultura brasileira. São Paulo (SP): Atlas, 1997. p. 273-292. 
FREITAS, A. B. Traços brasileiros para uma análise organizacional. In: MOTTA, F. C. P.; CALDAS, M. P. Cultura organizacional e cultura brasileira. São Paulo: Atlas, 1997. p. 3869.

FREITAS, M. E. Assédio Moral e Assédio Sexual: faces do poder perverso nas organizações. Revista de Administração de Empresas -RAE. São Paulo: FGV, v. 41, n. 2, p. 8-19, 2001.

FREITAS, M. E. Cultura Organizacional: evolução e crítica. São Paulo: Thomson Learning, 2007.

FREITAS, M. E.; HELOANI, R.; BARRETO, M. Assédio moral no trabalho. Cengage Learning, São Paulo, 2008.

HOFSTEDE, G. The Hofstede Centre. Dimensions. [19--]a. Disponível em: $<$ http://geerthofstede.com/dimensions.html>. Acesso em: 20 abr. 2014.

HOFSTEDE, G. Geert Hofstede \& Gert Jan Hofstede. Dimensions of national Cultures. [19--]b. Disponível em: $<$ http://www.geerthofstede.com/dimensions-of-national-cultures $>$. Acesso em: 20 abr. 2014.

MCGREGOR, D. The human side of enterprise. New York: McGraw-Hill, 1960.

MOTTA, F. C. P.; CALDAS, M. P. Introdução: Cultura organizacional e cultura brasileira. In: MOTTA, F. C. P.; CALDAS, M. P. Cultura organizacional e cultura brasileira. São Paulo: Atlas, 1997. p. 15-21.

NUNES, T. S. Assédio moral no trabalho: o contexto dos servidores da Universidade Federal de Santa Catarina. Florianópolis, SC, 2011. 281p. Dissertação (Mestrado) Universidade Federal de Santa Catarina, Centro Sócio-Econômico. Programa de PósGraduação em Administração, 2011.

PRATES, M. A. S.; BARROS, B. T. O estilo brasileiro de administrar: sumário de um modelo de ação cultural brasileiro com base na gestão empresarial. In: MOTTA, F. C. P.; CALDAS, M. P. Cultura organizacional e cultura brasileira. São Paulo: Atlas, 1997. p. 5569.

RAMOS, A. G. A nova ciência das organizações: uma reconceituação da riqueza das nações. 2. ed. Rio de Janeiro: Fundação Getúlio Vargas, 1989.

RORATO, R.; DIAS, E. D. Cultura organizacional no setor público: um estudo junto a um departamento administrativo de uma universidade federal brasileira. Revista de Administração da Universidade Federal de Santa Maria, v. 4, n. 3, p. 341-351, 2011.

SCHEIN, E. H. Cultura organizacional e liderança. São Paulo: Atlas, 2009.

SILVA, N. As Interfaces entre cultura e aprendizagem organizacional: o caso de uma empresa do setor cerâmico de Santa Catarina. Florianópolis, SC, 2001. VIII, 470f. Tese (Doutorado) - 
Universidade Federal de Santa Catarina, Centro Tecnológico. Programa de Pós-Graduação em Engenharia de Produção, 2001.

TRIVIÑOS, A. N. S. Introdução à pesquisa em ciências sociais: a pesquisa qualitativa em educação. São Paulo: Atlas, 1992.

UFSC. Universidade Federal de Santa Catarina. Estatuto da UFSC. Florianópolis: UFSC, 1978. Disponível em: < http://cun.orgaosdeliberativos.ufsc.br/estatuto-da-ufsc/>. Acesso em: 21 ago. 2016.

UFSC. Universidade Federal de Santa Catarina. Plano de Desenvolvimento Institucional 2010 a 2014. Florianópolis: UFSC, 2010. Disponível em:

$<$ http://pdi.paginas.ufsc.br/files/2011/03/PDI-2010-2014.pdf $>$. Acesso em: 25 abr. 2014.

UFSC. Universidade Federal de Santa Catarina. Departamento de Planejamento e Gestão da Informação. UFSC EM NÚ́MEROS. Florianópolis: UFSC, 2015. Disponível em: < http://dpgi.seplan.ufsc.br/ufsc-em-numeros/>. Acesso em: 19 set. 2016.

VIEIRA, E. F.; VIEIRA, M. M. F. Funcionalidade burocrática nas universidades federais: conflito em tempos de mudança. Revista de Administração Contemporânea. Curitiba, v. 8, n. 2, p. 181-200, 2004. 